\title{
Experimental and theoretical investigation of precipitate coarsening rate in Z-phase strengthened steels
}

Rashidi, Masoud; Odqvist, Joakim; Johansson, Lennart; Hald, John; Andrén, Hans-Olof; Liu, Fang

Published in:

Acta Materialia

Link to article, DOI:

10.1016/j.mtla.2018.09.024

Publication date:

2018

Document Version

Peer reviewed version

Link back to DTU Orbit

Citation (APA):

Rashidi, M., Odqvist, J., Johansson, L., Hald, J., Andrén, H-O., \& Liu, F. (2018). Experimental and theoretical investigation of precipitate coarsening rate in Z-phase strengthened steels. Acta Materialia, 4, 247-254. https://doi.org/10.1016/j.mtla.2018.09.024

\section{General rights}

Copyright and moral rights for the publications made accessible in the public portal are retained by the authors and/or other copyright owners and it is a condition of accessing publications that users recognise and abide by the legal requirements associated with these rights.

- Users may download and print one copy of any publication from the public portal for the purpose of private study or research.

- You may not further distribute the material or use it for any profit-making activity or commercial gain

- You may freely distribute the URL identifying the publication in the public portal 


\title{
Experimental and theoretical investigation of precipitate coarsening rate in Z-phase strengthened steels
}

\author{
Masoud Rashidi ${ }^{\mathrm{a} *}$ Joakim Odqvist ${ }^{\mathrm{b}}$, Lennart Johansson ${ }^{\mathrm{c}}$, John Hald ${ }^{\mathrm{d}}$, Hans-Olof \\ Andrén ${ }^{\mathrm{e}}$, Fang Liu ${ }^{\mathrm{a}}$ \\ a Department of Industrial and Materials Science, Chalmers University of Technology, SE-412 96 \\ Gothenburg, Sweden \\ ${ }^{\mathrm{b}}$ Department of Materials Science and Engineering, KTH Royal Institute of Technology, SE-100 44 \\ Stockholm, Sweden \\ ${ }^{c}$ Siemens Industrial Turbomachinery AB, SE-612-83 Finspong, Sweden \\ ${ }^{\mathrm{d}}$ Department of Mechanical Engineering, Technical University of Denmark, DK 2800 Kgs. Lyngby, \\ Denmark \\ ${ }^{\mathrm{e}}$ Department of Physics, Chalmers University of Technology, SE-412 96 Gothenburg, Sweden \\ * Corresponding author, e-mail masoud.rashidi@chalmers.se
}

\begin{abstract}
Two Z-phase strengthened $12 \% \mathrm{Cr}$ steels were investigated: they are similar in composition, however one steel contains $\mathrm{Nb}$ and the other contains Ta. Z-phase precipitates $(\mathrm{CrMN}, \mathrm{M}=\mathrm{Nb}$ or $\mathrm{Ta})$ provide precipitation hardening for creep resistance at $650^{\circ} \mathrm{C}$ in these steels. Experimental data based on the transmission electron microscopy investigation of the size evolution of Z-phase precipitates during isothermal ageing at $650^{\circ} \mathrm{C}$ show that the Ta-based Z-phase benefits from a five times smaller coarsening constant compared to the Nb-based Z-phase. Theoretical calculations show that this is attributed to the smaller diffusivity of Ta compared to $\mathrm{Nb}$ in the steel matrix. Besides, comparing the size of the Ta-based Z-phase precipitates in the gauge and grip portion of a crept specimen, it is shown that Z-phase coarsens faster under stress.
\end{abstract}

Keywords: precipitate; coarsening rate; creep; electron microscopy; diffusivity. 


\section{Introduction}

Increasing the steam temperature and pressure in fossil-fuel steam power plants leads to a higher thermal efficiency and a lower $\mathrm{CO}_{2}$ emission and fuel consumption. The maximum allowed steam temperature and pressure are determined by the long-term creep and corrosion resistance of economically viable materials. The 9-12\% chromium martensitic steels are used in the critical components of fossil fuel steam power plants such as main steam pipes and turbine rotors, due to their good corrosion and creep resistance, high thermal conductivity, and low thermal expansion coefficient $[1,2]$. Precipitation hardening is regarded as the main mechanism to achieve long-term creep resistance and chromium is responsible for the corrosion resistance of these alloys. $\mathrm{M}_{23} \mathrm{C}_{6}(\mathrm{M}=\mathrm{Cr}, \mathrm{Fe}), \mathrm{Fe}_{2}(\mathrm{~W}, \mathrm{Mo})$, and $\mathrm{MX}(\mathrm{M}=\mathrm{Nb}, \mathrm{V}, \mathrm{X}=\mathrm{C}, \mathrm{N})$ are the main precipitates contributing to the strength of the conventional 9-12\% Cr steels for steam temperatures up to $600^{\circ} \mathrm{C}[1,2]$. In order to increase the steam temperature and pressure in such power plants to $650^{\circ} \mathrm{C}, \mathrm{Z}$-phase $(\mathrm{CrMN}, \mathrm{M}=\mathrm{Nb}$ or Ta) strengthened steels [3, 4] were recently developed. Z-phase strengthened steels combine a high chromium content to provide sufficient corrosion resistance, and a fine distribution of Z-phase precipitates to provide precipitation hardening for long-term creep resistance.

To evaluate whether or not a precipitate type can contribute to the strength of a material, one needs to study the nucleation, growth and coarsening behavior of the precipitates. Z-phase does not nucleate on its own and it was shown that Z-phase forms via indiffusion of $\mathrm{Cr}$ to the MX precipitates [5]. This process in conventional $12 \% \mathrm{Cr}$ steel is very slow, so only a few Z-phase precipitates are formed. As Z-phase is the most stable nitride at the temperature of interest in these alloys, it grows rapidly at the expense of the relatively unstable MX precipitates. In Z-phase strengthened steels, a rapid transformation from MX to Z-phase leads to a fine distribution of Z-phase in the tempered condition or during the early stages of service. It was previously shown that such a fine distribution of Z-phase is achievable via stimulating the formation of Zphase (high $\mathrm{Cr}$ and low C) for Nb-based Z-phase [6] and Ta-based Z-phase [3].

The precipitation behavior is not only affected by the high temperature but also by strain during creep. Hättestrand and Andrén [7] studied the influence of strain on the precipitation behavior of $\mathrm{M}_{23} \mathrm{C}_{6}, \mathrm{VN}$ and Laves-phase during creep of $\mathrm{P} 92$ at $600^{\circ} \mathrm{C}$ and $650^{\circ} \mathrm{C}$. They reported an increase in the coarsening rate of $\mathrm{M}_{23} \mathrm{C}_{6}$ due to the effect 
of strain. The number density of Laves-phase precipitates appeared to be higher in the crept specimens compared to the aged ones. There was no significant difference on the VN precipitates between the crept and the aged specimen.

In this paper, both experimental and theoretical calculations were employed to study the coarsening rate for two types of $\mathrm{Z}$-phase: Ta and $\mathrm{Nb}$ based. Besides, the effect of strain on the coarsening behavior of Ta-based Z-phase is investigated.

\section{Experimental methods}

\subsection{Materials}

The trial steels investigated in this work were produced as $80 \mathrm{~kg}$ ingots by vacuum induction melting. The ingots were then hot rolled into $20 \mathrm{~mm}$ thick plates. The composition of investigated trial steels is provided in Table 1. These trial steels with either $\mathrm{Nb}$ (Z-Nb steel) or Ta (Z-Ta steel) contain a high $\mathrm{Cr}$ and a very low $\mathrm{C}$ concentration, in order to stimulate the formation of Z-phase and to achieve a fine distribution of stable Z-phase precipitates for precipitation hardening. A more detailed description of the alloy design is presented in Ref. [3, 4, 6]. Both trial steels were austenitized at $1150^{\circ} \mathrm{C}$ for $1 \mathrm{~h}$ and then cooled in air to room temperature. The steels were then aged for 1000,3000 , and $10,000 \mathrm{~h}$ at $650^{\circ} \mathrm{C}$. Since $\mathrm{Z}$-phase forms fastest at $650^{\circ} \mathrm{C}$ in $12 \% \mathrm{Cr}$ steels [8], no extra tempering treatment was performed.

To study the effect of strain on the coarsening behavior of Z-phase, a crept specimen of Z-Ta steel was studied. This creep specimen had been austenitized at $1050^{\circ} \mathrm{C}$ for 1 $\mathrm{h}$ and tempered at $700^{\circ} \mathrm{C}$ for $7 \mathrm{~h}$ before creep testing at $80 \mathrm{MPa} / 650^{\circ} \mathrm{C}$ for $6311 \mathrm{~h}$. Specimens prepared from the grip and from the gauge portion (a region with approximately $1 \%$ reduction of area) of this crept specimen were investigated.

In order to characterize the Z-phase precipitates in the trial steels, an FEI Titan 80-300 transmission electron microscope (TEM) equipped with an EDAX X-ray detector and a TIA energy dispersive X-ray (EDX) software were employed. High angle annular dark field (HAADF) and bright field $(\mathrm{BF})$ in the scanning transmission electron microscopy (STEM) mode were used to image the precipitates. EDX was used to 
analyze the chemical composition of individual precipitates in the trial steels. Atom probe tomography (APT) was employed to measure the solubility of $\mathrm{Nb}$ and $\mathrm{Ta}$ in the steel matrix of specimens aged for $10,000 \mathrm{~h}$ at $650^{\circ} \mathrm{C}$.

To prepare TEM specimens, discs $3 \mathrm{~mm}$ in diameter were cut from the steels with different heat treatment conditions and mechanically ground to the thickness of 100 $\mu \mathrm{m}$. The electron transparent specimens were prepared by electropolishing in $10 \%$ perchloric acid $+90 \%$ methanol at $-30^{\circ} \mathrm{C}$ and a bias voltage of $10 \mathrm{~V}$ using the twin-jet Struers Tenupol 5.

\subsection{Diffusivity calculation}

Using the Thermo-Calc software [9], with the thermodynamic database TCFE8 [10] and the mobility database MOBFE3 [11], the chemical diffusivity and the influence of Co on the diffusivity of $\mathrm{Ta}$ and $\mathrm{Nb}$ in the Fe bcc matrix at $650^{\circ} \mathrm{C}$ were calculated.

\subsection{Creep testing}

For creep testing, specimens austenitized at $1150^{\circ} \mathrm{C} / 1 \mathrm{~h}$ and tempered at $650^{\circ} \mathrm{C} / 24 \mathrm{~h}$ were used. The creep rupture testing was performed in accordance with Standard EN ISO 204:2009. The creep rupture tests were carried out at $650{ }^{\circ} \mathrm{C}$ under a constant load corresponding to 120,100 (Z-Nb only), or $80 \mathrm{MPa}$ using specimens of $7 \mathrm{~mm}$ in diameter, $50 \mathrm{~mm}$ in gauge and $135 \mathrm{~mm}$ in length. The creep tests were done on the specimens austenitized at $1150^{\circ} \mathrm{C} / 1 \mathrm{~h}$ and tempered at $650^{\circ} \mathrm{C} / 24 \mathrm{~h}$.

\section{Results and discussion}

\subsection{Creep testing at $650^{\circ} \mathrm{C}$}

Figure 1 shows the creep rupture strength of both trial steels at $650^{\circ} \mathrm{C}$. The creep strength of the Z-Ta steel is higher than that of the Z-Nb steel tested for all stress levels. The data for Z-Ta at $100 \mathrm{MPa}$ is missing. However, we have creep data at $100 \mathrm{MPa}$ for a different heat treatment of Z-Ta, austenitizing at $1050^{\circ} \mathrm{C} / 1 \mathrm{~h}$ and tempering at $700^{\circ} \mathrm{C} / 7 \mathrm{~h}$. This gave a rupture time at $650^{\circ} \mathrm{C}$ of approximately $4300 \mathrm{~h}$, which is in accordance with the data in the diagram. 


\subsection{Characterizing Z-phase}

Figure 2 shows an STEM-EDX elemental mapping taken from the Z-Nb and Z-Ta steels aged for $3000 \mathrm{~h}$. The $\mathrm{Cr}$ and $\mathrm{Nb}$ map in the $\mathrm{Z}-\mathrm{Nb}$ steel and the $\mathrm{Cr}$ and Ta map in the Z-Ta steel show Z-phase precipitates. The W map shows Laves-phase precipitates in both steels. Laves-phase contains approximately 16 at. \% $\mathrm{Cr}$ [12], which is slightly higher than the $\mathrm{Cr}$ content in the matrix (approximately 13 at.\%), which gives some contrast in the Cr maps. Typical EDX spectra from such precipitates are also provided in Figure 2. Although STEM images yield similar contrast for Z-phase and Laves phase, EDX analysis can identify the two phases unambiguously.

Z-phase precipitates are mainly found in a blade-like morphology, since Z-phase grows in specific orientations with the steel matrix. A typical example of such a morphology taken from Z-Ta steel aged for 10,000 h, together with the schematic drawing of Zphase precipitates, are shown in Figure 3. The projection of wide and narrow surfaces of the Z-phase precipitates are shown in Figure 3 a. Similar morphology was also reported previously by Cipolla [5] for $\mathrm{Nb}$ and $\mathrm{V}$ based Z-phase.

There are two commonly used methods to measure the size of precipitates in 9-12\% $\mathrm{Cr}$ steels. The first approach [13], known as particle diameter (PD), is the average of the longest dimension and the dimension perpendicular to the longest dimension of the precipitates. The second approach, known as equivalent circle diameter (ECD) [7, 13], is to measure the area of the precipitates using image-processing software and calculate the equivalent circle diameter. These techniques are commonly used for spherical particles or for bulky particles with irregular morphology. Zhu et al. [14] showed that these two approaches provide similar results for $\mathrm{M}_{23} \mathrm{C}_{6}$ carbides. Thus, the PD approach was used as one of the methods to measure the size of the Z-phase precipitates.

Another method was also employed in the present study, i.e. the equivalent sphere radius (ESR) of the precipitates, since Z-phase precipitates are formed in the blade-like morphology. The obtained data from the PD method, $d_{\max }$ and $d_{\min }$, were treated the following way: the $d_{\max }$ was considered as the length of the precipitates. If $d_{\min } / d_{\max }>$ 0.5 , then $d_{\min }$ was considered as the width of the precipitates, otherwise $d_{\min }$ was considered as the thickness. The length, width and thickness of approximately 100 
precipitates were measured. ESR was calculated based on the average volume of the precipitates:

$L \times T \times W=\frac{4}{3} \pi r^{3}$

Equation

1

where $\mathrm{L}, \mathrm{T}$, and $\mathrm{W}$ are the average length, thickness, and width of the Z-phase precipitates. The obtained data from ESR and the radius measured via the PD method were then compared.

\subsection{Experimental coarsening rate of Z-phase}

Figure 4 shows the evolution of Z-phase precipitates in the trial steels during ageing at $650^{\circ} \mathrm{C}$ for 1000,3000 , and 10,000 h. Both $\mathrm{Nb}$ and Ta-based Z-phase precipitates were found with the blade-like morphology in the $1000 \mathrm{~h}$-aged specimens, and they kept the same morphology over ageing up to 10,000 h. In Figures $4 \mathrm{a}$ and b, Z-phase precipitates are oriented in such a way that the wide surfaces of most precipitates are shown, while in Figures $4 \mathrm{c}$ and e, the narrow surfaces of most precipitates are displayed, and in Figure $4 \mathrm{f}$, both the wide and narrow surfaces of Z-phase precipitates are projected.

Figure 5 shows the size distribution (PD approach) of Z-phase precipitates in the Z-Ta and Z-Nb steels. It is obvious that Z-Ta benefits from a much smaller precipitate size compared to Z-Nb. After $1000 \mathrm{~h}$ ageing at $650^{\circ} \mathrm{C}$, precipitates in Z-Ta distributed in a very narrow size range (with smaller average size) compared to those in $\mathrm{Z}-\mathrm{Nb}$, which can explain for the very different creep strength of the steels at the high stress level (120 MPa). Ageing up to $3000 \mathrm{~h}$ gave a bimodal distribution of precipitate size for both trial steels. The bi-modal size distribution shifted to larger precipitate size after 10,000 $\mathrm{h}$ ageing, which was more pronounced for the $\mathrm{Nb}$-based $\mathrm{Z}$-phase compared to the Tabased Z-phase. Even though, no quantitative data is reported on the number density of the Z-phase precipitates in two steels, it is worth mentioning that the number density of Ta-based Z-phase appears to be higher than that of for Nb-based Z-phase. Number density and size of the precipitates are of two important parameters defining their contribution to the strength of the materials. 
Figure 6 shows the size evolution of Z-phase precipitates in both trial steels measured via the PD and ESR methods. As can be seen, both methods show similar results. Apparently for larger precipitates in the $\mathrm{Z}-\mathrm{Nb}$ steel aged for $10,000 \mathrm{~h}$, the difference between the two methods increases. The measured ESR of the Nb-based Z-phase is $18.7 \pm 0.8,27.5 \pm 1.1$, and $38.2 \pm 1.4 \mathrm{~nm}$ for specimens aged for 1000, 3000, and 10,000 $\mathrm{h}$, respectively. The ESR of the Ta-based Z-phase is $5.1 \pm 0.2,18.6 \pm 0.6$, and $23.8 \pm 0.8$ $\mathrm{nm}$ for specimens aged for 1000,3000 , and $10,000 \mathrm{~h}$, respectively.

In Z-Nb steel, previous APT investigation on the specimen aged for $24 \mathrm{~h}$ at $650^{\circ} \mathrm{C}$ [5] showed the presence of precipitates rich in $\mathrm{Cr}, \mathrm{N}$ and $\mathrm{Nb}$. These precipitates had some fluctuations in the composition, which was attributed to the ongoing dissolution and phase transformation from $\mathrm{NbN}$ to Z-phase. For Nb-based Z-phase, it was also shown that the in-diffusion of $\mathrm{Cr}$ to the $\mathrm{NbN}$ precipitates continues up to $3000 \mathrm{~h}$, when $\mathrm{Z}$-phase reaches its equilibrium composition all over the precipitate [6]. The same behavior is also expected for the Ta-based Z-phase. The fluctuation in the composition of the precursor precipitates to Z-phase and dissolution and transformation of precipitates is probably the main reason for the rapid increase in the size of the precipitates from 1000 $\mathrm{h}$ aged specimens to $3000 \mathrm{~h}$ aged ones. Thus, it was assumed that the increase in the size of the precipitates in this period belongs to the growth stage. Therefore, in order to exclude the growth stage, the experimental coarsening rate for Z-phase precipitates is measured for the precipitate size evolution (based on ESR) in the aged specimen for $3000 \mathrm{~h}$ to $10,000 \mathrm{~h}$ based on the well-known Ostwald ripening equation:

$r^{3}-r_{0}^{3}=K_{P} \cdot t$

Equation 2

where $r$ is the precipitate radius at time $t\left(10,000 \mathrm{~h}\right.$ in this investigation) and $r_{0}$ is the precipitate radius at time zero (3000 $\mathrm{h}$ in this investigation). The coarsening constant $K_{P}$ was determined to $1.4 \times 10^{-30}$ and $2.8 \times 10^{-31}\left(\mathrm{~m}^{3} \mathrm{~s}^{-1}\right)$ for the Nb-based and Ta-based Zphase, respectively. Thus at $650^{\circ} \mathrm{C}$ the measured coarsening constant for Nb-based Zphase is a factor of 5 larger than that for Ta-based Z-phase.

The coarsening constant for Ta-based Z-phase is in the same order of magnitude as that of the VN precipitates in the P92 steel. The coarsening constant was calculated for VN precipitates from the experimental data presented by Hättestrand and Andrén [7] for the P92 steel aged at $650^{\circ} \mathrm{C}$ for up to $10,000 \mathrm{~h}$. The radius of $\mathrm{VN}$ precipitates was 17.5 (as- 
tempered condition) and $21.5 \mathrm{~nm}\left(10,000 \mathrm{~h}\right.$ aged at $\left.650^{\circ} \mathrm{C}\right)$, which give a coarsening constant of $1.3 \times 10^{-31}\left(\mathrm{~m}^{3} \mathrm{~s}^{-1}\right)$.

\subsection{Calculated coarsening rate of Z-phase}

At present the Nb-based Z-phase has been thermodynamically assessed in the database TCFE8, but not the Ta-based Z-phase. This means that a full kinetic modeling of Zphase coarsening (using e.g. DICTRA, the diffusion model in Thermo-Calc) cannot be made for Z-Ta, and neither can the equilibrium solubilities of Ta and $\mathrm{N}$ be calculated. However, calculations of the coarsening constant using the model by Ågren et al. [15] can be made, if the diffusivity calculations for $\mathrm{Nb}$ and $\mathrm{Ta}$ in the matrix are combined with estimates of interfacial energies from DFT calculations and measured composition data from APT.

\section{Diffusivity of $\mathrm{Nb}$ and $\mathrm{Ta}$ in the matrix}

Using the Thermo-Calc software, the chemical diffusivity of Ta in the Z-Ta steel and $\mathrm{Nb}$ in the Z-Nb steel at $650^{\circ} \mathrm{C}$ was calculated to be $6.81 \times 10^{-19} \mathrm{~m}^{2} \mathrm{~s}^{-1}$ and $6.91 \times 10^{-18} \mathrm{~m}^{2} \mathrm{~s}^{-}$ ${ }^{1}$, respectively. Thus, Ta diffuses one order of magnitude slower than $\mathrm{Nb}$ in the ferrite matrix. Figure 7 shows the influence of the Co content in the steel on the diffusivity of $\mathrm{Ta}$ and $\mathrm{Nb}$ in the bcc matrix i.e. increasing the Co content of the matrix results in a slower diffusivity of $\mathrm{Ta}$ and $\mathrm{Nb}$ in the steel matrix.

\section{Interfacial energy of Z-phase}

Like NbN and TaN, Z-phase has a low misfit in the (100)z//(100) bcc plane which leads to disc or blade shaped precipitates with $(100)_{\text {matrix }}$ as the habit plane. This means that the total interfacial energy is dominated by this low misfit interface. Fors and Wahnström [16] have calculated the energy of this interface for all NaCl-type MX carbides and nitrides in bcc Fe using atomistic and elastic modeling, assuming a semicoherent interface containing interfacial dislocations. They found that the sum of chemical and elastic energy falls on a single curve that depends only on the misfit. Assuming that the chemical part of the interfacial energy in not dramatically different between $\mathrm{MX} / \mathrm{Fe}$ and Z-phase/steel matrix, we can use this curve to estimate the interfacial energy between Z-phase and matrix. For CrNbN two measurements of the 
lattice parameters exist in the literature, $\mathrm{a}=0.3029$ (all lattice parameters in $\mathrm{nm}$ ) and $\mathrm{c}=0.7360$ [17], as well as $\mathrm{a}=0.3037$ and $\mathrm{c}=0.7391$ [18].With a mean $\mathrm{az}=0.3033$ and assuming that the matrix lattice parameter is similar to that of bcc Fe, 0.2866, we arrive at a misfit $2\left(\mathrm{a}_{\mathrm{Z}}-\mathrm{a}_{\mathrm{Fe}}\right) /\left(\mathrm{az}+\mathrm{a}_{\mathrm{Fe}}\right)$ of $5.7 \%$. Likewise, the measured lattice parameters of CrTaN, $a=0.3004$ and $c=0.7334$ [17], give a misfit of 4.7\%. From the curve in Ref. [16] we then obtain interface energies of 0.85 and $0.71 \mathrm{Jm}^{-2}$ for $\mathrm{CrNbN}$ and $\mathrm{CrTaN}$, respectively.

\section{Solubilities of $\mathrm{Nb}$ and $\mathrm{Ta}$}

The solubilities of $\mathrm{Nb}$ and $\mathrm{Ta}$ in the steel matrix at $650^{\circ} \mathrm{C}$ is expected to be low; an equilibrium calculation for Z-Nb using TCFE8 gives a $\mathrm{Nb}$ solubility of 9.6 at.ppm (and a very low $\mathrm{N}$ solubility of only 97 at.ppb). Due to database limitations, no calculation can be made for Z-Ta. APT analysis was made of the matrix of the two steels after aging at $650^{\circ} \mathrm{C}$ for $10,000 \mathrm{~h}$. A dataset of approximately 4 millions atoms from the matrix of each of the steels gave the following matrix contents: Z-Nb 20.5 at.ppm $\mathrm{Nb}$, 89 ppm N, and 13.25 at.\% Cr; Z-Ta 17.4 ppm Ta, 87 ppm N, and 13.05 at.\% Cr. Thus, the measured solubility of $\mathrm{Nb}$ is of the same order of magnitude as the equilibrium value, but the measured $\mathrm{N}$ content is about three orders of magnitude larger than the calculated value. Also, the measured solubility in $\mathrm{Z}-\mathrm{Ta}$ is similar to that of $\mathrm{Nb}$ measured in Z-Nb.

\section{Composition of Z-phase}

The composition of the two Z-phases measured by APT are 35.7 at.\% Cr, 30.1\% Nb, and $28,85 \% \mathrm{~N}$ for $\mathrm{CrNbN}$ [6], and $35.37 \% \mathrm{Cr}, 25.5 \% \mathrm{Ta}, 33.9 \% \mathrm{~N}$ for $\mathrm{CrTaN}$ [12].

\section{Calculated coarsening constant}

A calculation of the coarsening constant can be made using the equation by Ågren et al. [15]:

$$
K_{P}=\frac{8}{9} \frac{\gamma V_{m}^{\beta}}{\sum_{i=1}^{C}\left[\left(x_{i}^{\beta}-x_{i}^{\frac{\alpha}{\beta}}\right)^{2} /\left(x_{i}^{\frac{\alpha}{\beta}} D_{i} / R T\right)\right]}
$$


where $\gamma$ is the interfacial energy, $V_{m}^{\beta}$ is the molar volume of the precipitate phase, $D_{i}$ is the diffusion coefficient of element $i$ in the matrix, $x_{i}^{\beta}$ is the mole fraction of element $i$ in the precipitate, and $x_{i}^{\alpha / \beta}$ is the mole fraction of element $i$ at the precipitate/matrix interface.

The result for Z-Nb is $K_{P}=1.11 \times 10^{-30}\left(\mathrm{~m}^{3} \mathrm{~s}^{-1}\right)$ and for Z-Ta $K_{P}=1.04 \times 10^{-31}\left(\mathrm{~m}^{3} \mathrm{~s}^{-1}\right)$. Thus the calculated coarsening constant for $\mathrm{CrTaN}$ is a factor of 10 smaller than that of $\mathrm{CrNbN}$, and the main reason for this is the ten times lower diffusivity of $\mathrm{Ta}$ than $\mathrm{Nb}$ in the steel matrix. The measured solubility of Ta in the matrix is only $15 \%$ smaller than that of $\mathrm{Nb}$, and the estimated interfacial energy in $\mathrm{Z}$-Ta is only $18 \%$ smaller than that of Z-Nb. It is interesting to note that the calculation of the coarsening constant is completely dominated by the $\mathrm{Nb}$ or Ta term in the equation. Thus, the low solubility of $\mathrm{N}$ is overwhelmed by the large diffusivity of $\mathrm{N}$. Not even replacing the measured $\mathrm{N}$ solubility by a thousand times smaller calculated value leads to any effect on the calculated coarsening constant.

Comparing the measured and calculated coarsening constants, the measured constants are $25 \%$ higher $(\mathrm{Z}-\mathrm{Nb})$ and a factor of 2.7 higher $(\mathrm{Z}-\mathrm{Ta})$ than the calculated ones. Considering the uncertainties in both calculated and measured data, the agreement for $\mathrm{Z}-\mathrm{Nb}$ must be regarded as good. The larger difference for Z-Ta suggests that the measured coarsening constant does not represent pure coarsening, but that there is still some growth at $3000 \mathrm{~h}$. Extrapolating the measured radius to $100,000 \mathrm{~h}$ using the experimental coarsening constant gives a precipitate radius of $47 \mathrm{~nm}$, i.e. twice the size at $10,000 \mathrm{~h}$. Using instead the calculated coarsening constant we obtain $36 \mathrm{~nm}$, i.e. an increase with only $50 \%$.

\subsection{The effect of Co}

The addition of Co into Z-phase strengthened steels is favorable. Firstly, Co reduces the affinity of $\mathrm{Cr}$ to the steel matrix and hence accelerates the phase transformation from MX to Z-phase [4]. Secondly, considering the very limited amount of $\mathrm{C}$ in the trial steels, the addition of $\mathrm{Co}$ as an austenite stabilizer avoids the formation of detrimental $\delta$-ferrite [19]. Thirdly, the addition of Co, see Figure 7, decreases the diffusivity of $\mathrm{Ta}$ and $\mathrm{Nb}$ in the steel matrix, which is a very important parameter 
controlling the coarsening behavior of Z-phase precipitates. The addition of Co increases the Curie temperature of the steel. Because diffusion depends on ferromagnetic state of the metals, the addition of Co is believed to slow down the diffusion of atoms [20].

Dudova et al. [21] reported a beneficial effect of Co in a 3wt.\% Co modified P92-type steel on the coarsening behavior of $\mathrm{M}_{23} \mathrm{C}_{6}$ precipitates during creep. The size of the $\mathrm{M}_{23} \mathrm{C}_{6}$ precipitates in the $3 \mathrm{wt} . \%$ Co modified P92 after creep testing was smaller than that of in the P92 steel.

\subsection{Effect of strain on Z-phase coarsening}

To study the effect of strain on the coarsening behavior of Ta-based Z-phase precipitates, specimens from the grip and gauge of a Z-Ta steel crept for $6311 \mathrm{~h}$ at $650^{\circ} \mathrm{C}$ were prepared for TEM investigations. The heat treatment for this crept specimen differs from the aged specimens of Z-Ta steel. The measured ESR of Z-phase precipitates in the grip and gauge of the crept specimen were 15.9 \pm 0.7 and $19.3 \pm 0.6$ $\mathrm{nm}$ respectively. Figure 8 shows STEM-BF micrographs of such precipitates in the ZTa steel.

Z-phase precipitates are $18 \%$ larger in the gauge portion, which is exposed to stress, compared to the grip portion, which is stress-free. There are possibly two reasons for such a phenomenon. Firstly, it might be due to the "solute drag effect" where substitutional atoms are carried by migrating dislocations [7], which increases the diffusivity of such elements for example Ta in the matrix. Secondly, as is shown in Figure 8, the interaction between dislocations and precipitates in the crept specimen leads to a higher effect of pipe diffusion to the precipitates [22]. Sawada et al. [23] reported that the number density of Z-phase precipitates were 2.5 times bigger in the gauge portion of the crept specimen compared to the grip portion in a $9 \% \mathrm{Cr}$ steel crept at $600^{\circ} \mathrm{C}$, which shows the influence of creep deformation on the Z-phase formation. It was assumed that the strain promoted the Cr diffusion enhancing the transformation from MX to Z-phase, and thus in the crept specimen more Z-phase was formed.

\section{Conclusions}


The coarsening constant at $650^{\circ} \mathrm{C}$ of two types of $\mathrm{Z}$-phase, $\mathrm{CrNbN}$ and $\mathrm{CrTaN}$, were investigated in two trial Z-phase strengthened steels both experimentally using TEM (based on the Ostwald ripening equation) during ageing for up to $10,000 \mathrm{~h}$, and theoretically based on the coarsening model by Ågren et al.

Both experimental and theoretical coarsening constants show that Ta-based Z-phase coarsens much slower compared to the $\mathrm{Nb}$-based Z-phase during isothermal ageing at $650^{\circ} \mathrm{C}$. The experimental coarsening constant for $\mathrm{Z}-\mathrm{Nb}$ was determined to $1.4 \times 10^{-30}$ $\left(\mathrm{m}^{3} \mathrm{~s}^{-1}\right)$ and for Z-Ta to $2.8 \times 10^{-31}\left(\mathrm{~m}^{3} \mathrm{~s}^{-1}\right)$, a factor of 5 smaller. The theoretical coarsening constant for $\mathrm{Z}-\mathrm{Nb}$ is only slightly smaller than the experimental value, whereas the theoretical constant for Z-Ta is considerably smaller (a factor of 2.7) than the experimental value, suggesting that the experimental value represents a mixture of growth and coarsening. The measured solubility of $\mathrm{Nb}$ and $\mathrm{Ta}$ in the steel matrix (20.5 at. ppm $\mathrm{Nb}$ and 17.4 at. ppm Ta) are close to each other. The estimated interfacial energy based on the Z-phase and matrix misfit is also not very different from each other. Thus, the factor of 10 smaller diffusivity of Ta in the steel matrix compared to that of $\mathrm{Nb}$ is believed to be the main reason for the lower coarsening rate of the Ta-based Zphase.

Comparison between the size of Z-phase precipitates in the gauge and grip portions of a crept specimen showed that Ta-based Z-phase coarsens faster in the gauge portion, which is strained, compared to the grip portion, which is stress-free and does not deform. After $6300 \mathrm{~h}$ at $650^{\circ} \mathrm{C}$, precipitates in the gauge section $(1 \%$ strain) were $18 \%$ larger than in the grip portion.

\section{Acknowledgments}

Financial support from the Swedish Energy Agency, KME (contract number: 710), the Research Foundation of VGB in Germany (contract number: 397), and the EU FP7 ZULTRA (contract number: 309916) is gratefully acknowledged. FL is partly funded via LIGHTer, a program financed within Strategic Innovation Areas, a mutual venture between VINNOVA, the Swedish Energy Agency, and Formas. Torsten-Ulf Kern of Siemens AG is also gratefully thanked for fruitful discussions. 


\section{References}

[1] F. Abe, "Development of creep-resistant steels and alloys for use in power plants," in Structural Alloys for Power Plants, 2014, pp. 250-293.

[2] J. Hald, "Microstructure and long-term creep properties of 9-12\% Cr steels," Int. J. Press. Vessel. Pip., vol. 85, no. 1-2, pp. 30-37, 2008.

[3] F. Liu, M. Rashidi, L. Johansson, J. Hald, and H.-O. Andrén, “A new 12\% chromium steel strengthened by Z-phase precipitates," Scr. Mater., vol. 113, pp. 93-96, 2016.

[4] H. K. Danielsen and J. Hald, "Influence of Z-phase on Long-term Creep Stability of Martensitic 9 to 12\% Cr Steels," VGB PowerTech, vol. 5, pp. 6873, 2009.

[5] L. Cipolla, H. K. Danielsen, D. Venditti, P. E. Di Nunzio, J. Hald, and M. A. J. Somers, "Conversion of MX nitrides to Z-phase in a martensitic 12\% Cr steel," Acta Mater., vol. 58, no. 2, pp. 669-679, 2010.

[6] M. Rashidi, H.-O. Andrén, and F. Liu, "Core-shell structure of intermediate precipitates in a Nb-based Z-phase strengthened 12\% Cr steel," Microsc. Microanal., vol. 23, no. 2, pp. 360-365, 2017.

[7] M. Hättestrand and H.-O. Andrén, "Influence of strain on precipitation reactions during creep of an advanced 9\% chromium steel," Acta Mater., vol. 49, no. 12, pp. 2123-2128, 2001.

[8] H. K. Danielsen, P. E. Di Nunzio, and J. Hald, "Kinetics of Z-Phase Precipitation in 9 to 12 pet Cr Steels," Metall. Mater. Trans. A, vol. 44, no. May, pp. 2445-2452, 2013.

[9] J. O. Andersson, T. Helander, L. Höglund, P. F. Shi, and B. Sundman, "Thermo-Calc and Dictra, Computational tools for materials science," Calphad, vol. 26, pp. 273-312, 2002.

[10] “Thermo-Calc Software TCFE8 Steels/Fe-alloys database."

[11] "Thermo-Calc Software MOBFE3 Steels/Fe-alloys mobility database."

[12] M. Rashidi, L. Johansson, H.-O. Andrén, and F. Liu, "Microstructure and mechanical properties of two Z-phase strengthened $12 \% \mathrm{Cr}$ martensitic steels: 
the effects of Cu and C," Mater. Sci. Eng. A, vol. 694, pp. 57-65, 2017.

[13] O. Prat, J. Garcia, D. Rojas, C. Carrasco, and A. R. Kaysser-Pyzalla, "Investigations on coarsening of $\mathrm{MX}$ and $\mathrm{M}_{23} \mathrm{C}_{6}$ precipitates in $12 \% \mathrm{Cr}$ creep resistant steels assisted by computational thermodynamics," Mater. Sci. Eng. A, vol. 527, no. 21-22, pp. 5976-5983, 2010.

[14] N. Q. Zhu, L. Lu, Y. L. He, L. Li, and X. G. Lu, "Coarsening of $\mathrm{M}_{23} \mathrm{C}_{6}$ Precipitates in an Fe-Cr-C Ternary Alloy," J. Iron Steel Res. Int., vol. 19, no. 9, pp. 62-67, 2012.

[15] J. Ågren, M. T. Clavaguera-Mora, J. Golczewski, G. Inden, H. Humar, C. Sigli, and Ågren, "Group 3: Application of Computational Thermodynamics to Phase Transformation Nucleation and Coarsening," Calphad, vol. 24, no. 1, pp. 41$54,2000$.

[16] D. H. R. Fors and G. Wahnström, "Theoretical study of interface structure and energetics in semicoherent $\mathrm{Fe}(001) / \mathrm{MX}(001)$ systems $(\mathrm{M}=\mathrm{Sc}, \mathrm{Ti}, \mathrm{V}, \mathrm{Cr}, \mathrm{Zr}$, Nb, Hf, Ta; X=C or N)," phys. Rev. B, vol. 82, pp. 195410-1-13, 2010.

[17] P. Ettmayer, "Die Struktur der Komplexnitride $\mathrm{NbCrN}$ und $\mathrm{Ta}_{1-\mathrm{x}} \mathrm{Cr}_{1+\mathrm{x}} \mathrm{N}$," Monatshefte für Chemie, vol. 102, pp. 858-863, 1971.

[18] D. H. Jack and K. H. Jack, "Structure of Z-phase, NbCrN," J. Iron Steel Inst., vol. 209, pp. 790-792, 1972.

[19] L. Helis, Y. Toda, T. Hara, H. Miyazaki, and F. Abe, "Effect of cobalt on the microstructure of tempered martensitic $9 \mathrm{Cr}$ steel for ultra-supercritical power plants," Mater. Sci. Eng. A, vol. 510-511, no. C, pp. 88-94, 2009.

[20] J. P. Sanhueza, D. Rojas, O. Prat, J. Garcia, R. Espinoza, C. Montalba, and M. F. Melendrez, "Precipitation kinetics in a $10.5 \% \mathrm{Cr}$ heat resistant steel: Experimental results and simulation by TC-PRISMA/DICTRA," Mater. Chem. Phys., vol. 200, pp. 342-353, 2017.

[21] N. Dudova, A. Plotnikova, D. Molodov, A. Belyakov, and R. Kaibyshev, "Structural changes of tempered martensitic 9\%Cr-2\%W-3\%Co steel during creep at $650^{\circ}$ C," Mater. Sci. Eng. A, vol. 534, pp. 632-639, 2012.

[22] G. Eggeler, "The effect of long-term creep on particle coarsening in tempered martensite ferritic steels," Acta Metall., vol. 37, no. 12, pp. 3225-3234, 1989. 
[23] K. Sawada, H. Kushima, and K. Kimura, "Z-phase Formation during Creep and Aging in 9-12\% Cr Heat Resistant Steels," Iron Steel Inst. Japan Int., vol. 46, no. 5, pp. 769-775, 2006.

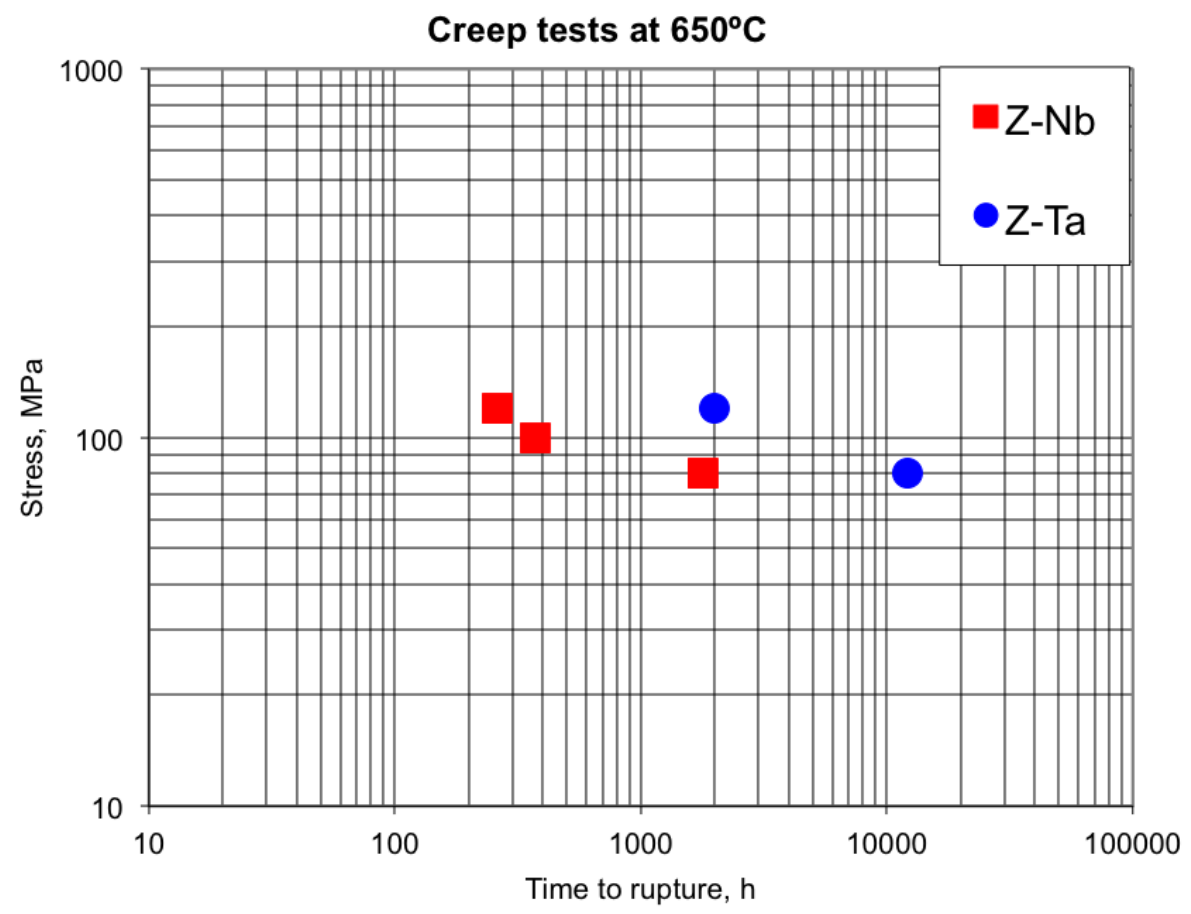

Figure 1. Creep rupture strength for the Z-Nb and Z-Ta steels at $650^{\circ} \mathrm{C}$. (Both steels were austenitized at $1150^{\circ} \mathrm{C} / 1 \mathrm{~h}$ and tempered at $650^{\circ} \mathrm{C} / 24 \mathrm{~h}$. No data for $100 \mathrm{Mpa}$ is available for Z-Ta. 

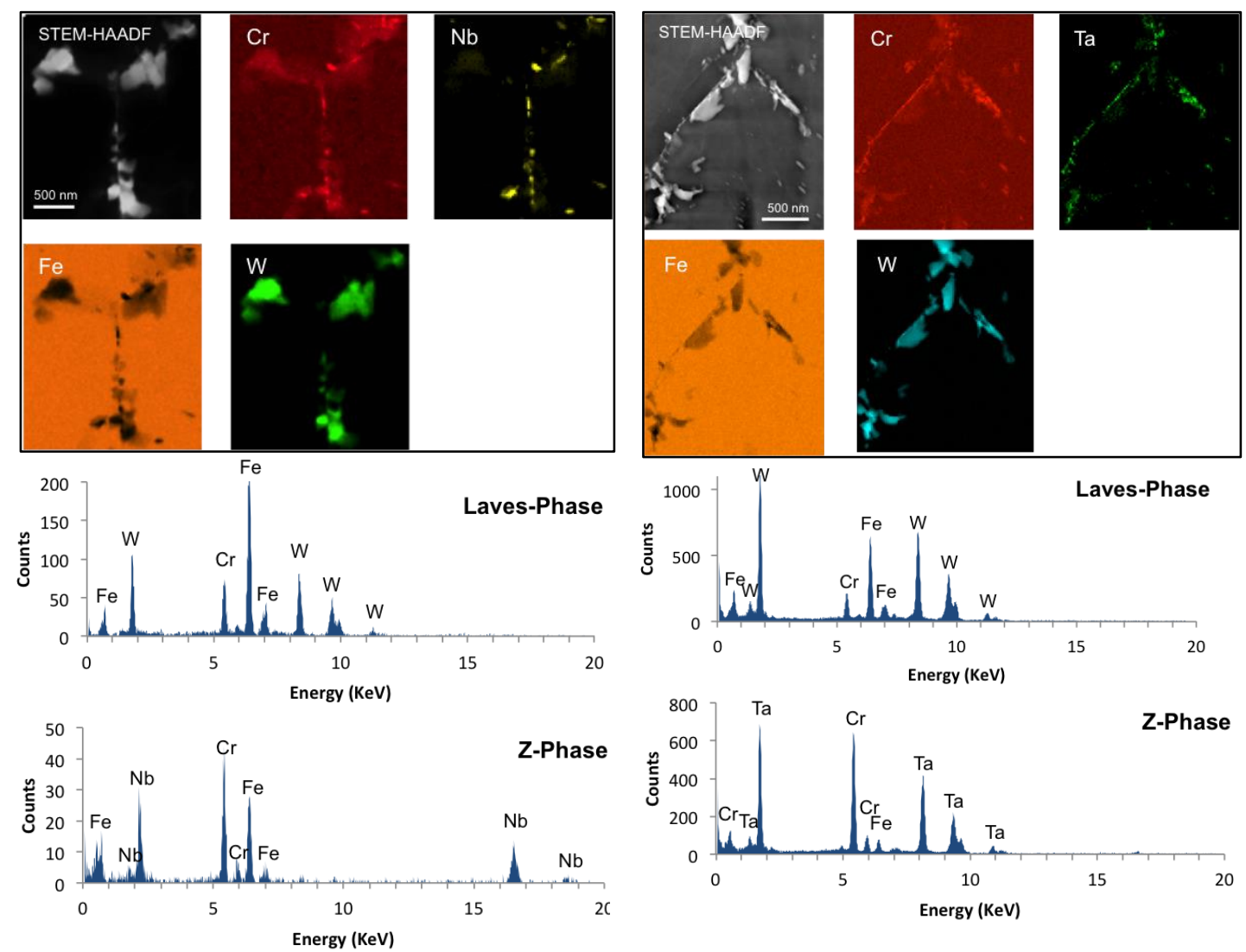

Figure 2. STEM-EDX elemental mapping of the Z-Nb (left side) and Z-Ta (right side) trial steel aged for $3000 \mathrm{~h}$ at $650^{\circ} \mathrm{C}$. Typical EDX spectra from Laves-phase and Z-phase precipitates are also provided in both steels. Note that the difference in the Fe peak in the spectra for Laves-phase precipitates is attributed to the contribution from the steel matrix to the EDX measurements due to the difference in the size of the analyzed precipitates. 

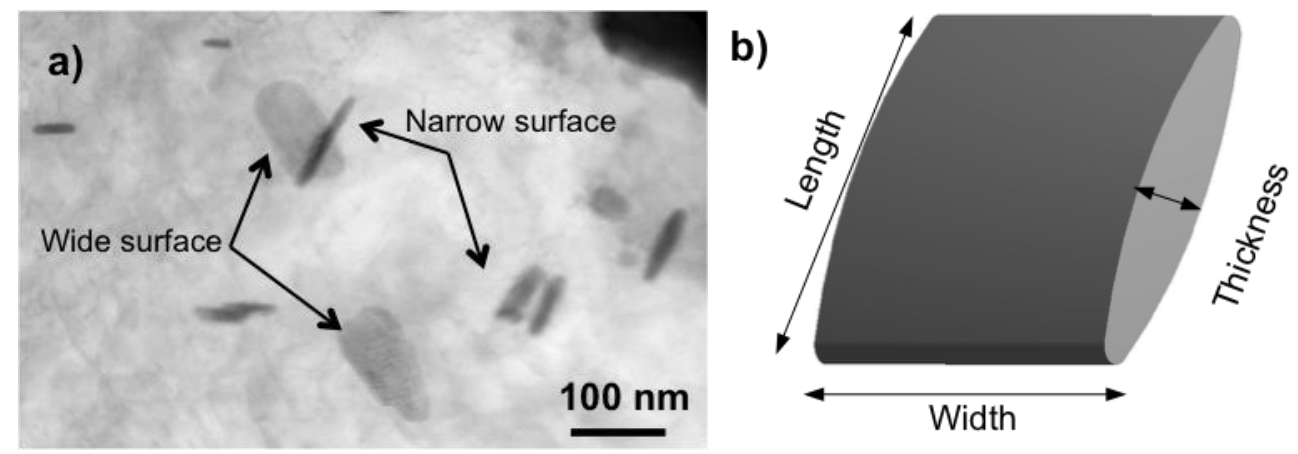

Figure 3. STEM/BF micrograph of Z-Ta steel aged for $10,000 \mathrm{~h}$ at $650^{\circ} \mathrm{C}$ showing the typical morphology of Z-phase precipitates in TEM images and b) a schematic drawing showing the morphology of Z-phase precipitates in three dimensions.
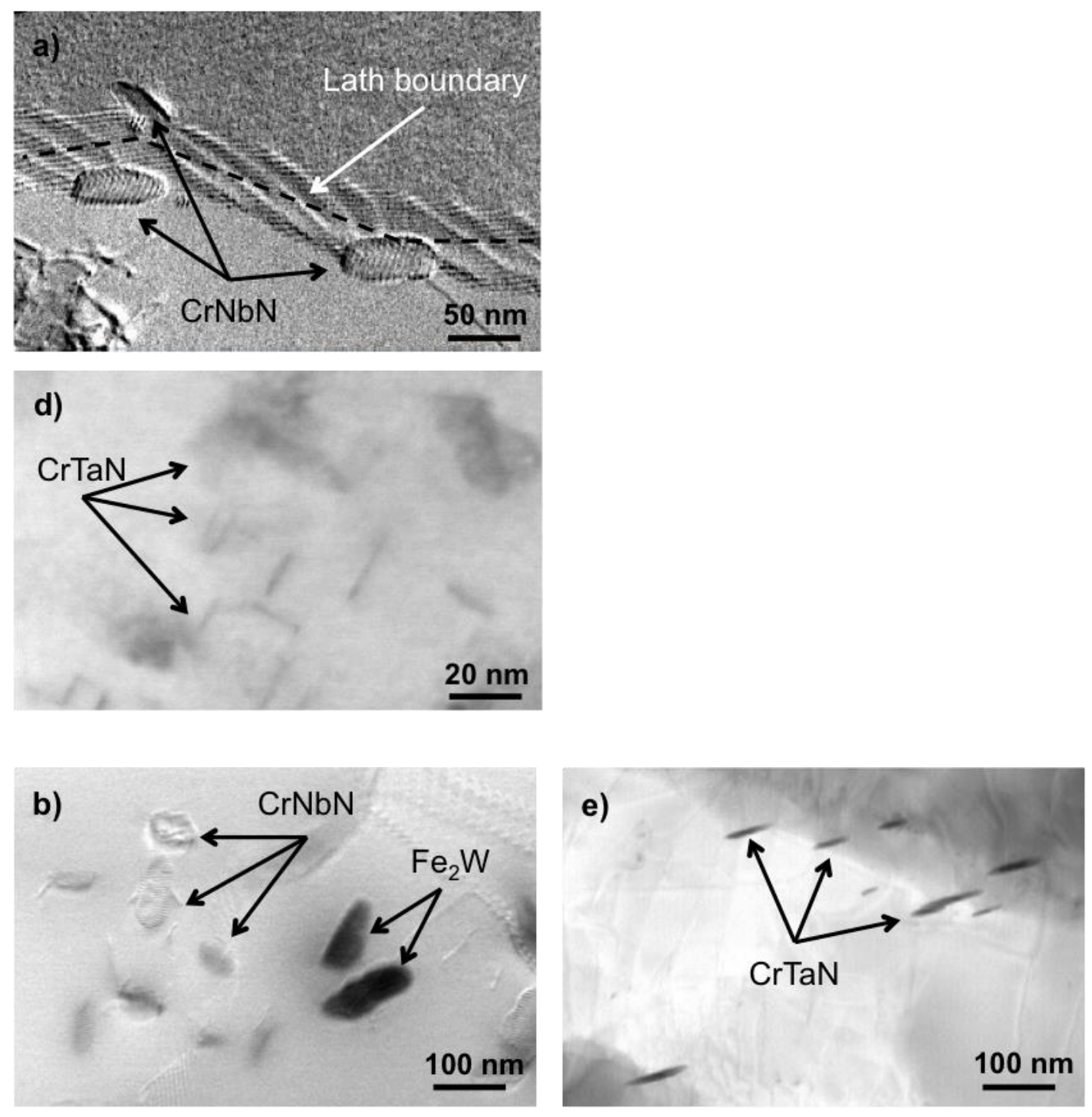

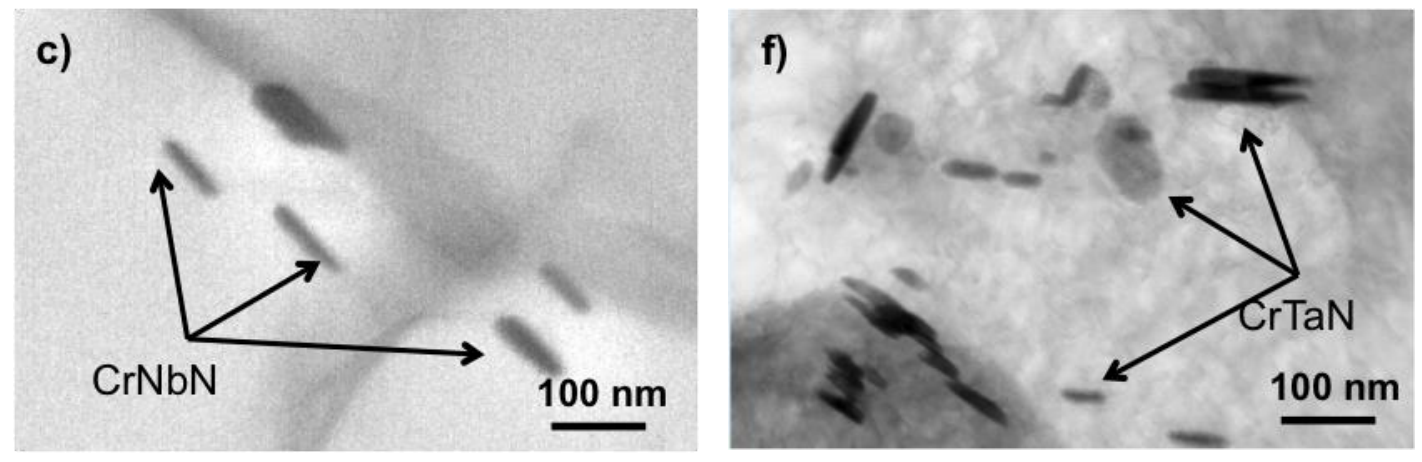

Figure 4. STEM/BF micrographs showing the evolution of Z-phase precipitates in the Z-Nb trial steel aged at $650^{\circ} \mathrm{C}$ for a) $\left.\left.1000 \mathrm{~h}, \mathrm{~b}\right) 3000 \mathrm{~h}, \mathrm{c}\right) 10,000 \mathrm{~h}$ and the Z-Ta trial steel aged at $650^{\circ} \mathrm{C}$ for d) $1000 \mathrm{~h}$, e) $3000 \mathrm{~h}$, and f) 10,000 h.

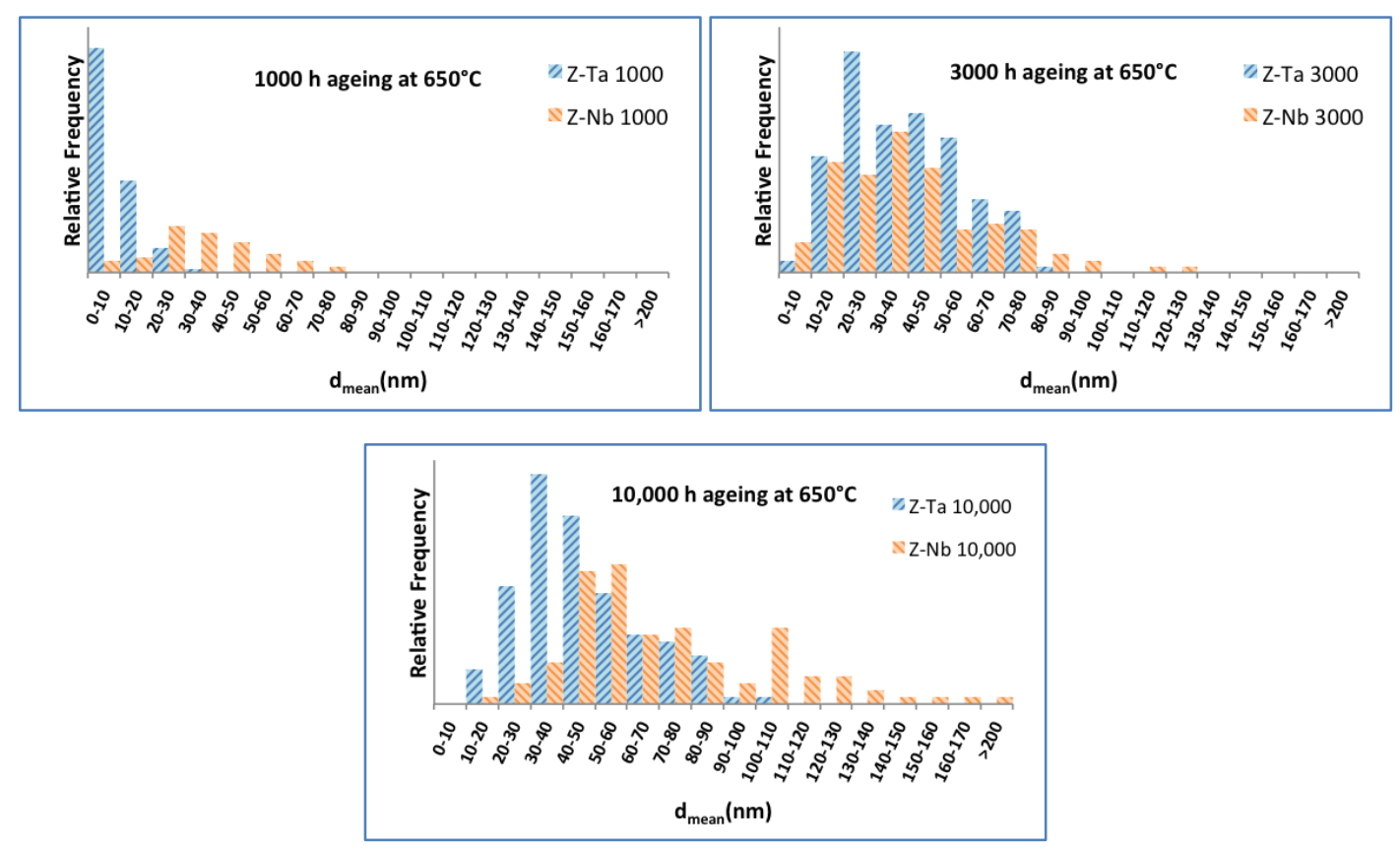

Figure 5. Size distribution ( $d_{\text {mean }}$ measured via PD method) of Z-phase precipitates after 1000, 3000, and 10,000 hageing at $650^{\circ} \mathrm{C}$. 


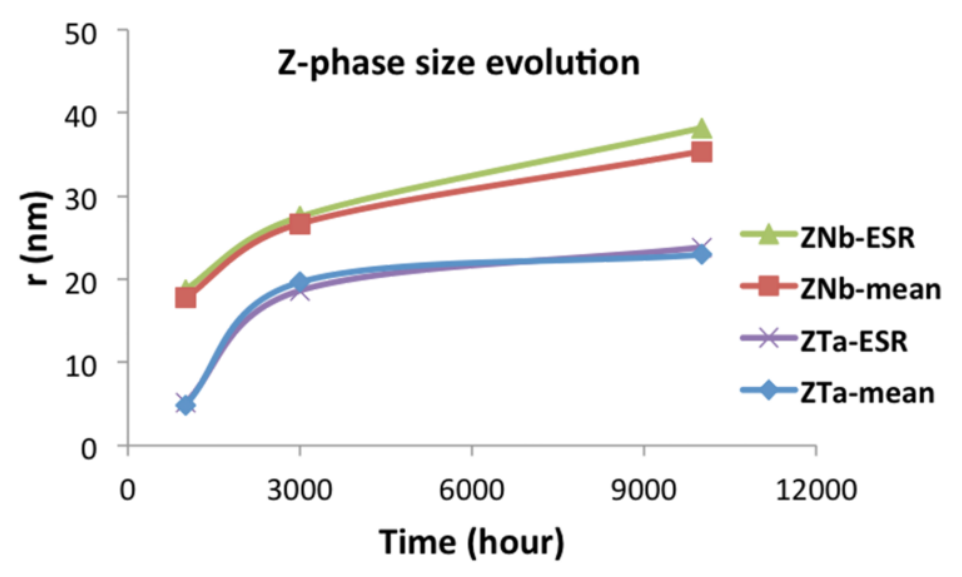

Figure 6. The size evolution of Z-phase precipitates during ageing at $650^{\circ} \mathrm{C}$ measured via equivalent sphere radius (ESR) and the radius measured via "particle diameter" method. The lines are drawn to guide the eyes.

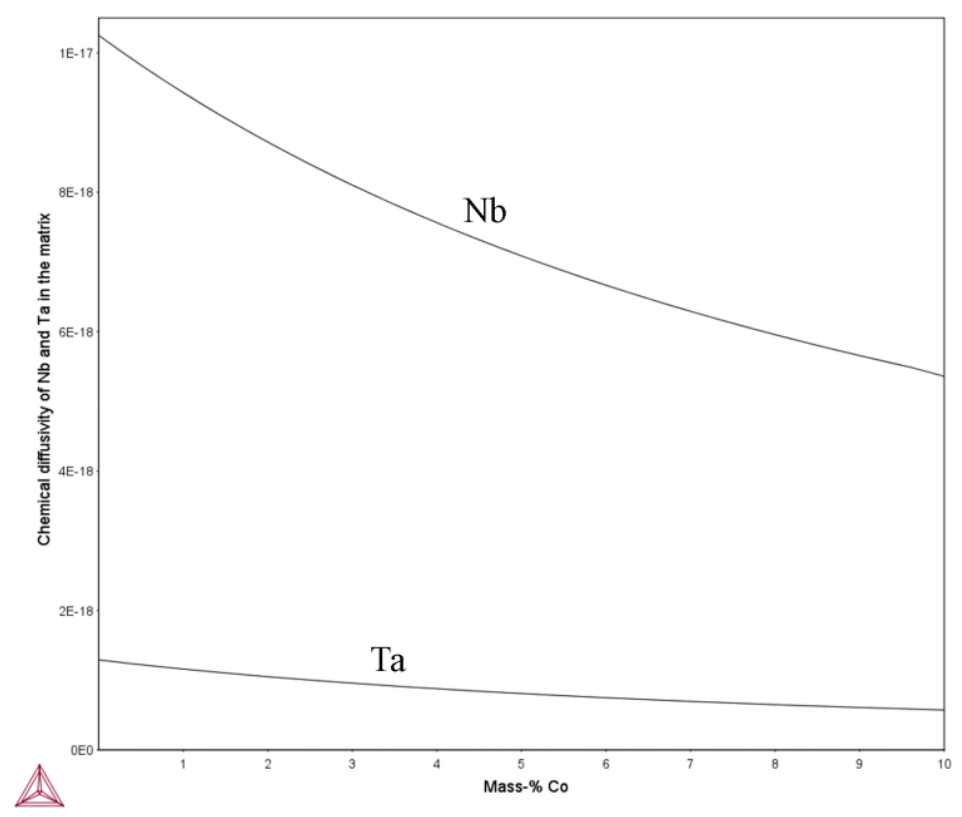

Figure 7. The influence of the Co content on the diffusivity of $\mathrm{Nb}$ and Ta at $650^{\circ} \mathrm{C}$ in the ferrite matrix. Calculations were made based on the compositions of Z-Nb and Z-Ta except for Co (and Fe) that was varied between 0 and $10 \mathrm{wt} . \%$. 

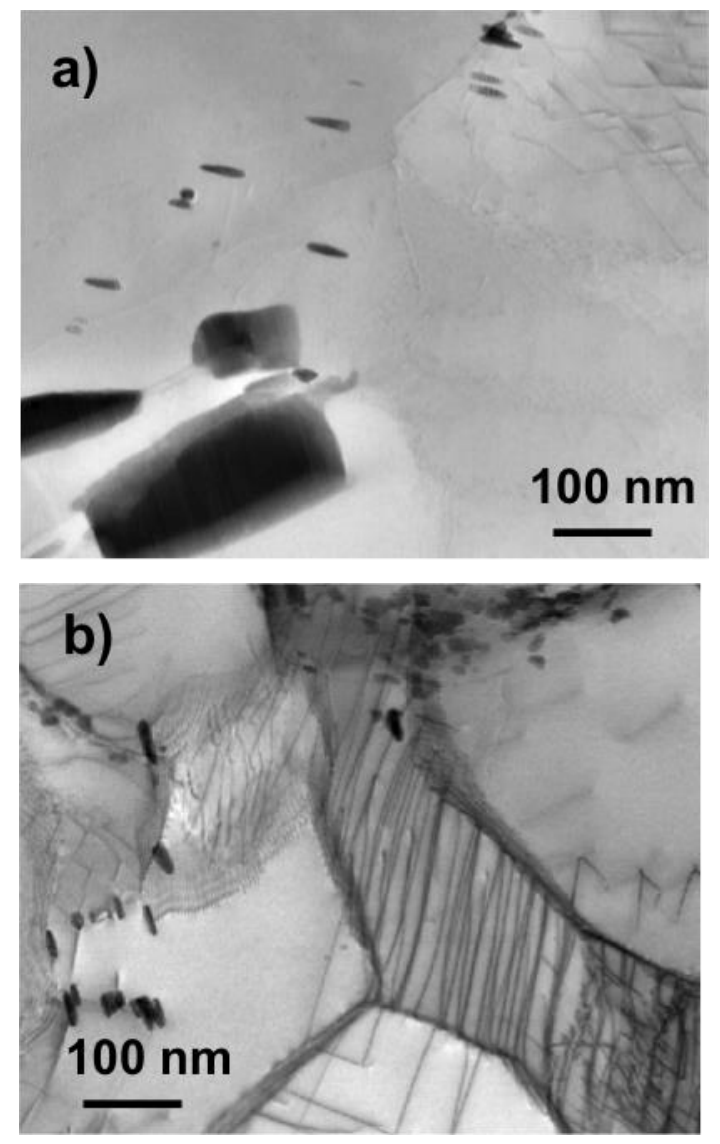

Figure 8. STEM/BF micrograph of the Z-Ta steel $(1050 / 1 \mathrm{~h}+700 / 7 \mathrm{~h})$ from a) the grip of a crept specimen (thermally aged) b) the gauge of the crept specimen (corresponding to the region with $1 \%$ reduction of area).

Table 1. Chemical composition of two investigated Z-phase strengthened steels, Fe in balance.

\begin{tabular}{ccccccccccccc}
\hline Steel & & $\mathbf{C}$ & $\mathbf{M n}$ & $\mathbf{S i}$ & $\mathbf{C r}$ & $\mathbf{N i}$ & $\mathbf{W}$ & $\mathbf{C o}$ & $\mathbf{B}$ & $\mathbf{N}$ & $\mathbf{N b}$ & $\mathrm{Ta}$ \\
\hline \multirow{2}{*}{ Z-Nb } & at\% & 0.02 & 0.50 & 0.60 & 12.64 & 1.47 & 0.87 & 5.2 & 0.02 & 0.15 & 0.16 & - \\
& wt\% & 0.005 & 0.50 & 0.30 & 11.64 & 1.47 & 2.82 & 5.4 & 0.004 & 0.036 & 0.26 & - \\
\hline \multirow{2}{*}{ Z-Ta } & at\% & 0.02 & 0.49 & 0.60 & 12.84 & 0.50 & 0.89 & 7.0 & 0.02 & 0.13 & - & 0.12 \\
& wt\% & 0.005 & 0.48 & 0.30 & 11.79 & 0.50 & 2.90 & 7.3 & 0.004 & 0.033 & - & 0.39 \\
\hline
\end{tabular}

